Published by the University of KwaZulu-Natal https://journals.ukzn.ac.za/index.php/JICBE (C) Creative Commons With Attribution (CC-BY) Journal of Inclusive cities and Built environment. Vol. 2 Issue 1

How to cite: R.A Hayangah. 2022. The Planning Dilemma in Upgrading of Informal Settlements in South African Cities: A Practitioners Perspective on the Inclusivity Paradox. Conference Proceedings for International Symposium on Inclusive-Cities: Achieving Inclusive Cities Through A Multidisciplinary Approach, 2021 28-30 June. Journal of Inclusive cities and Built environment. Vol. 2 Issue 1, Pg 29-34.

\title{
THE PLANNING DILEMMA IN UPGRADING OF INFORMAL SETTLEMENTS IN SOUTH AFRICAN CITIES: A PRACTITIONERS PERSPECTIVE ON THE INCLUSIVITY PARADOX
}

\section{By R.A Hayangah}

Published 31 January 2022

\begin{abstract}
Abstract

This article examines the inclusivity paradox and the inter play of power and influence that has led to the planning dilemmas observed in the upgrading of informal settlements in South Africa. It is based on the perspectives of a practicing planner that recognizes that inclusivity can facilitate the development of socially cohesive and sustainable settlements. The planning dilemmas are apparent at all levels of the planning process, from conceptualization, design, preparation, and implementation when the voices of planners can be subsumed or lost given the dynamic working environments in the local authorities. There is also a strong correlation between the historical exposition to colonialism and apartheid legacy that was oppressive and racially discriminatory. This has led to adoption an empathetic approach in development control in the cities and towns. The consequences of the post democratic freedom and mobility is the increasing in formalization of many municipalities with varying degrees of expansion and growth. The planning fraternity has no desire to replicate the oppressive land use zonings and forced removals of the past. It is concluded that inclusivity though an elusive concept is necessary in the upgrading of informal settlements occupied by some of the most vulnerable members of the society and with a background of oppression, aggression and bias in the allocation and development of living spaces.
\end{abstract}

KEY WORDS informal settlements upgrading, planning, inclusivity, dilemma, practitioner

Rosemary Awuor Hayangah: Former Senior Lecturer, University of KwaZulu Natal, Durban 4001, S.A. Director, KTE Planning Consultants. 


\section{INTRODUCTION}

Rapid urbanisation narrowly defined within the context of informalisation of the South African cities has created a "nightmare" in many municipal authorities in the country as they struggle to contain, maintain and provide the desired infrastructure and housing needs of their citizenry. This has been compounded by a myriad of actions taken by stakeholders/operatives, communities and activities taken by the municipalities to respond to informality. This has led to the development of highly dynamic, often politically loaded informal yet powerful spaces which tend to be at the "periphery of municipal governance" and outside the norms and standards of town planning regulations.

The question is how planning respond to informality should so that there is meaningful resolution to the challenges arising from informal settlements formation, occurrence and subsequent upgrading. Some have argued that planners are complicit by omission; complacent by in action; that they are either silent by non-intervention or complacently silent by non-meaningful engagement with the citizenry that occupy the informal settlements; they have surrendered to political pressures/ power and choose to remain at the periphery. Indeed, are there realistic social compacts in the upgrading of informal settlements and to what extent are the planners and the communities engaged in the drafting of social compacts that inform the preparation of informal settlements upgrading plans? The dilemma is to what extent are these processes inclusive and from whose perspective.

\section{METHODOLOGY}

This article is based on the author's perspectives as a practicing planner; observation of planners' engagements in the preparation and implementation of informal settlements upgrading plans. It is also informed by appropriate secondary sources. The intention of this article is to provoke reflection on the manner in which the current informal settlements upgrading strategy/ approach has become a predicament to planners at best and a "thorny" issue at the worst in the planning of municipalities in South Africa in general. To what extent therefore should the planners embrace the upgrading of informal settlements? What should be their role? How should planners handle apparent policy contradictions/tensions in the governance/management of informal settlements at the municipal level? Cognizance is taken of the fact that the Municipality is the Planning Authority within their areas of jurisdiction. To what extent does this apparent power base inform the upgrading of informal settlements, influence approach to planning and upgrading of informal settlements? How power is therein utilized in practice to bring about the desired physical outcome in the upgrading of informal settlements.

\section{CHALLENGES AND GAPS IN THE UPGRADING OF INFORMAL SETTLEMENTS}

\subsection{INTRODUCTION}

Informalisation of the towns and cities of South Africa continue unabated as an expression of the nature of urbanisation that is taking place in the country. It is deeply rooted on the country's colonial and apartheid past history. Some of the challenges that have plagued informal settlements in the country include:

- $\quad$ Persistent \& deeply entrenched spatial inequality \& inequity (well into the post democratic era)

- Deprived and unhealthy living environment

Lack of basic infrastructural services

- Social cohesion challenges and common service delivery protests

Policy conflicts \& non-compliance with regulations (SPLUMA, 2013; Housing Policy; Environmental Health Act etc)

Poorly/weakly /inadequately implemented policy instruments \& related regulations compliance challenges (National Upgrading Support Programme (NUSP); Municipal Upgrading Units as the case may be).

\subsection{CONCEPT OF INCLUSIVITY}

The concept of Inclusivity is elusive and lack a universal definition. However, it as a recognisable threads of agreement in which there is imbalance or lop-sidedness depending on the given persuasion. Given that the preferential definition will be governed by the paradigm that informs the main focus and intended outcome whether pragmatic, practical, social, or economic as the case may be. These may include but not restricted to the following:Feelings of deprivation/dissatisfaction with a given action deemed to favour another and preferentially enjoys certain privileges/ benefits.

- $\quad$ Exclusion e.g. from participation in a given activity by design or inadvertently to favour another above the other person(s).

- Discrimination (by gender, class, race etc.)

- $\quad$ Lack of social cohesion (social; segregation; isolation etc.)

- $\quad$ Feeling of oppression (social perspective - lack of cohesion; Economic - livelihoods deprivation; spatial perspectives - spatial inequality and inequity.

The above aspects of inclusivity operating in the same space, can lead to contestations, conflicting approaches, and strategies which the spatial planner has to navigate and contend in the upgrading of informal settlements. Hence, the issue of competency and capacity of the planners comes into question. The planner can no longer afford to remain complacent or at the periphery of issues that have a direct impact on the upgrading of informal settlements in general and within the Municipality for which they have planning responsibility. It is therefore vital that the planner of the local municipality must have clear definition of the concept of inclusivity as informed by the shared vision of the given municipality, stakeholders, and citizenry. This is a formidable task as the lack of clear definition of inclusivity could lead to lack of intervention, complacency or a lack lustre approach to the detriment of the informal settlements upgrading process in practice. Inclusive upgrading of informal settlements will be informed 
by the definition adopted by the given city.

Examples of the myriad of definitions that have been put forward by various writers is appended below. An inclusive city may be defined as: A City: -

- Where all its people have access to basic services.

- Where people have access to employment opportunities to engage in productive livelihoods.

- That recognises people's cultural rights and provides amenities and public spaces for people to express these rights.

- Where people can find creative expression in arts \& heritage.

- Where people can show their talents \& sports and take part in community activities.

- That recognises the human capital of all its people \& actively tries to enhance this through appropriate programmes.

- That cherishes and propagates human rights

- That is proactive in meeting the development challenges as well as having the foresight to plan ahead \& mitigate against new challenges

- Where people can have political freedom and political expression

- That is socially cohesive and spatially integrated.

- Where everybody feels welcome regardless of race, ethnicity, nationally, background or class (Inclusive Cities Conference, 2007).

\subsection{HISTORICAL PERSPECTIVES AND DEVELOPMENT CONTROL}

Historical exclusion in South Africa is a product of colonialism and apartheid that promoted the deeply entrenched discrimination based on race, colour, and physical segregation which was in force for over century. The discriminatory policies were pervasive and affected all aspects of life in the country including human settlements. These aspects are well documented (Strauss, 2019; Parnell, 1995) some of which are as listed below:

- Frequent forced relocations (mostly black Africans)

- Punitive legislation (local authorities prohibited Africans [tenants] from adapting or improving their homes Kirk, 1991 as cited in Strauss, 2019).

Under provision of services in African areas

- Prohibition of Africans to own land

- Selective complacency in infrastructure provision mostly in the non-white areas.

- Use of law to advance systematic disposition, spatial segregation, political control \& Socio-economic exclusion (Strauss, 2019:136).

- Use of public health - disease outbreak to relocate blacks and remove them from areas of proximity to the white areas.

- NIMBY Concept of "not in my backyard" some of the concepts which are still practised variously but probably from both a class and socio-economic perspective to some extent at the present time particularly with respect to low income (informal settlements).

There are various pieces of legislation which are vital if one must have a complete understanding of some of the witnessed aggressive/negative responses to some of the decisions planners may make on paper but fail to implement in practice. Some of these are listed because of the historical association and impact on the deeply entrenched spatial inequality extant in South Africa with serious implication to housing in general and informal settlements upgrading in particular:

- $\quad$ Black Land Act 27 of 1913 (allocated $87 \%$ of land to Whites and $13 \%$ to Blacks) dispossession/relocation

- Development Trust \& Land Act 18 of 1936 (Control of spatial planning)

Black (Urban Areas) Act 21 of 1923 (enabled segregated residential areas for black residents in vicinity of urban areas.

- Group Areas Act 41 of 1950 (enabled zoning of land use by racial groups dictating on where to live \& work

The physical expression of actions undertaken based on these laws (but not restricted to them) and subsequent policies resulted in grave spatial inequality/inequity which is a challenge recognised by the Spatial Planning Land Use Management Act (SPLUMA) (2013) which aims to address these injustices. These historical factors have created a dilemma for the planners in particular and the state in general as it strives to improve the living standards of the marginalised/poor that are found in the informal settlements. The planner therefore has to be sensitive to the impact of the historical occurrences in the decision that they make need to embrace inclusivity by ensuring the application of social compacts that are generated together with the beneficiary communities.

\subsection{DEVELOPMENT CONTROL AND FUTURE OF THE CITIES}

The history of unjustified and exclusionary treatment of blacks based on race and forced relocation has influenced how planning has responded to the growth and expansion of informal settlements. It is apparent that planning has been responding to symptoms rather than the root causes of the problems associated with the upgrading of informal settlements. This perhaps explains why most of the upgrading plans that have been produced within the last decade by various municipalities and NUSP have not been implemented to the detriment of the cities who would benefit greatly from improved living conditions of their citizenry. 


\section{DISCUSSIONS}

\subsection{THE OPENING ARGUMENT}

The challenge to those working within the built environment profession such as planners is how to navigate the planning of informal settlements that might require relocation without invoking the past bitter forced removal experiences. This could perhaps explain the reluctance sometimes observed in the lack of intervention or action on part of the planners in the management of many of the informal settlements that are often located in precarious environments. There is also the issue of mushrooming informal settlements in a number of cities especially the Metros many of which have a "land Invasion Response Units" to stop the establishment of an informal settlement before it can have a foothold of a give piece of land in the municipality. Indeed, there is an urgent need for the planners to become more creative in the way in which the poor can be harmoniously integrated into the cities structures and systems without resulting into land invasion. Upgrading of some of the informal settlements may be seen as attempts to achieve integration even though at a very small scale within the context of the location of informal settlements across the municipalities.

How do the planners institute development control to ensure that they do not end up with a city of slums/ informal settlements without invoking past grievances while at the same time ensuring that the municipalities continue to develop in an orderly fashion. Planning must therefore the sensitive to historical injustices and of necessity formulate new ways to respond to the challenges of post democratic era informal settlements formation. The ineffectiveness of the upgrading plans that have been generated with the support of NUSP and the various metros is partly due to the adoption of western based models \& solutions (Strauss) 2019; AwuorHayangah, 1996) to situations that are uniquely South African tampered by colonialism, apartheid and entrenched poverty arising from centuries of dispossession and deprivation of the black South Africans.

\subsection{SCALE GROWTH \& EXPANSION OF INFORMAL SETTLEMENTS}

Informal settlements growth and expansion have been phenomenal in post democratic era which ushered in political and social freedom and has resulted into increased urbanisation. The massive growth and expansion of informal settlements extant in the country may be seen as the failure of development control departments and the seemingly "helplessness" of the planners and the local municipalities to deal with the informalisation of their towns and cities. The scale of formation of new informal settlements \& their physical expansion, calls for a different approaches /alternative strategies. This should emanate from the planning fraternity and the academia alike to generate new knowledge and promote the need to challenge the status quo for the development of inclusive and sustainable human settlements for the poor.

\subsection{APPROACH \& STRATEGY IN UPGRADING OF INFORMAL SETTLEMENTS}

The country-wide current approach to the upgrading of informal settlements has to a large extent been spear headed by the National Department of Human Settlements (NDHS) that has used NUSP as an instrument to offer support to municipalities in the upgrading of informal settlements. The preparation of upgrading plans is outsourced to consultants that are not necessarily planning firms which could also account for the lack of planning assuming a central position in the upgrading plan's preparation. This arrangement is problematic and has led to the production of plans that are not fully integrated at the municipal scale and often lack a holistic planning assessment. Could this be a problem of dilemma of upgrading of plans that are either Finance - Led (upgrading grants) or plans that are Consultant-Driven with the Municipality seemingly playing a complacent role so that communities can benefit from the projects? The municipalities are expected to play an increasingly active role in the upgrading process by directly identifying consultants to support them in the preparation of upgrading and implementation of the plans. It hoped that a Local Municipality - Led approach to upgrading of informal settlements will lead to a more inclusive process and attention to details that is often lacking from External-Led planning processes.

\subsection{INTERROGATION OF UPGRADING PLANS}

The quality and type of plans generated have a great impact on achieving the desired outcome of an upgrading process. An interrogation of why many upgrading plans generated have failed to achieve intended objectives is partly due to quality and content of the plans and models adopted. It was also established that the planners/municipalities lacked a tool to rapidly evaluate generated which was a hindrance in the determination of the quality. A simple matrix has been generated that includes an examination of the following qualities of a given plan: integrity, credibility, validity, adequacy and sustainability (Hayangah, 2020). From these key concepts, the author generated a simple matrix setting out Assessment Criteria for quality of upgrading plans. These are: depth, flexibility, accessibility (accessibility index), land suitability, disaster risk analysis and mitigation; integration, implementability and Sustainability. Depth and content of the plans can be enriched through inclusive participatory processes during the plan preparation stage (design, collection) as informed by agreed social compacts.

\subsection{DEVELOPMENT CONTROL}

Upgrading of an informal settlement sharing a fence with an Airport as was observed in one of the projects in practice, has serious consequence. In the long term, one of the uses will have to be relocated because they lack complementarity from a planning and health perspective. It will be costly project which could have been avoided if an inclusive and holistic approach had been adopted at the onset. Those who supported the in-situ upgrading of this informal settlement, were under the misguided belief that the beneficiaries henceforth legitimately will occupy strategically placed land as part of integration/inclusion in the city's planning system. This is true due to security of tenure to the beneficiaries but at what cost? This was spatial inclusivity to address past injustice but without consideration of the holistic 
elements that lead to the establishment of integrated viable settlements.

The explanation for such planning error may be attributable to a number of issues as expounded on below:

Use or participation of inexperienced planners who lacked capacity and failed to expose the dangers of the in-situ upgrading of this informal settlement. Planning also appeared to have taken secondary rather than a primary role in the preparation of the Upgrading Plan for the informal settlement. This is also a situation where it could be a sin of omission, complacency, helplessness, lack of political power (adopting a subservient role) and/or lack negotiation skills to ensure that planning inputs are not ignored or side-lined. Moreover, the planners failed to apply the relevant sections of the legislation that would have prohibited the in -situ upgrading of the informal settlement which was an outright case for relocation.

The dominance of those with power (politicians) that upgrading the settlement might be politically expedient but disastrous and expensive in the long term. Obvious challenges emanating from the noise of taking off and landing of the big planes will be a health hazard to infants, pregnant women and risk to flight accidents which though not common can happen when a settlement is on the flight path of aeroplanes.

In addition, the safety of the airport is compromised as the planes are exposed to dangers from possible saboteurs in the future. Thirdly, relocation of the people is also bound to traumatise the beneficiary community should such a decision be made. This is inevitable when proper land use control measures will be invoked.

Indeed the fourth aspect is a challenge to the planners who are to ensure that planning rules and regulations are not unduly relaxed even in State - led projects. The developments should be subjected to the same rigour of examination that is accorded to developments from the public and the private sector alike.

\subsection{UNINTENDED CONSEQUENCES OF POLICY IMPLEMENTATION}

The example of the in-situ upgrading plan that shares the fence with the airport could also be regarded as an unintended consequence of policy implementation when some parts of the public sector systems are not in sync with one another. In this instance, the focus was on the grant and the desire of the local authority to ensure their subjects were beneficiaries of the grant provided without taking into account the local locational development dynamics which were erroneously missed or ignored from the Externally-Led planning process. Moreover, there are those who would argue that the Housing Policy Code encourages in-situ upgrading of informal settlements, but this policy implementation should not take precedence of observing proper planning regulations as demonstrated by the case study presented above on sharing fence with the informal settlement.

\subsection{INCLUSIVITY PARADOX AND THE PLANNER}

The dilemma created by historical outcomes of the planning practice resulted in spatial injustices that persists in almost all the cities of South Africa. A legacy of the apartheid and colonial eras. Finding a solution has been elusive to both the planners and the municipal authorities despite the existence of a plethora of laws and regulations to redress the past historical injustices. Indeed, the planners might have the desire to upgrade the informal settlements within their areas of jurisdiction as genuine response to making the cities more inclusive to the marginalised communities living within the informal settlements but will have to a make decision that are at times problematic. For instance, at what point will the locational factors rather than politics be the defining factor in the upgrading process of informal settlements? Another scenario would be at what point would planning norms and standards take precedence over the grants/or financial support? The most appropriate approach will be invoking of an inclusive process where all relevant stakeholders, actors and beneficiaries work together. The concepts of inclusivity and social compacts become critical to successful implementation of successful upgraded settlements. At what point does inclusivity take precedence over other elements in the upgrading process?

Fourthly, current planning practice relies heavily on externally/consultant planning support rather than Municipal PlannerLedPlanning production which brings into question whose vision is being reflected in the final plan output, which is often a product of tokenism rather than inclusive participation by the beneficiaries. Lastly, there is need to deliberate on the longterm consequences of the widespread acceptance of upgrading informal settlements given their scale in terms of size and their physical expansion. Is this a blessing or a curse to the future of the South African cities? This is an issue which the planners of the respective municipalities have to grapple with.

\section{CONCLUSIONS}

The planning dilemma encountered in the upgrading of informal settlements has been identified at various levels from the planning approaches/strategies; power dynamics (influence \& political); tools and instruments; historical factors to the capacity of the Planners within the respective local authorities. The complex power dynamics operating in the municipal space in terms of influence and finance can silence the voice of spatial planners which may lead to token inclusivity yet they are deemed to be part and parcel of the decision making process. The political pressures and grant availability are critical in any development process and would result in unbalanced relationship which discretionary decision will be made in their favour. The historical exposition of colonialism and apartheid legacy with their inhumane forced removals has placed empathetic situations where there is avoidance re-invoking past anger by decisions that may relate to forced removals. This might lead to inactivity or silence by the planners who may not invoke the necessary legislation to impose strict development control measures that are unpopular. However, this is an opportunity for an inclusive approach and for coming to agreements through the use of social compacts. Dilemma also faced at policy implementation level which therefore renders the inclusivity most relevant. It is indeed concluded that inclusivity at all the several of planning process in the upgrading of informal settlements will lead to the development of socially cohesive and sustainable upgraded settlements. 


\section{REFERENCES}

Alhassan Ziblim (2013) The Dynamics of Informal Settlements Upgrading in South Africa: Legislative and Policy Context, Problems, Tensions, and Contradictions. A Study Commissioned by Habitat for Humanity International/ EMEA Office Bratislava, Slovakia.

Awuor-Hayangah, R. (1996). Urban Land Use Planning Process and Practice in Kenya: A Case Study of Siaya and Kisumu Districts. Unpublished Ph.D. Thesis, UWCC (UK).

Hayangah R.A. (2020) Informal Settlements Upgrading Plans Content and Quality Management. Report prepared for the National Department of Human Settlements (NUSP). Pretoria.

Inclusive Cities Conference (2007) Mapping challenges and opportunities in contemporary urban Africa

Kirk, JF (1991) "Race, class, liberalism, and segregation: The 1883 Native Strangers' Location Bill in Port Elizabeth, South Africa" International J of African Historical Studies 24(2):293321

Masiteng S (2013) In-Situ Upgrading of Informal Settlements: A Case study of Barcelona 1 - Lamontville, Durban. University of KwaZulu-Natal.

Misselhorn (2017) A Progrmme Management Toolkit for Metros: Preparing to Scale Up Informal Settlements Upgrading in South Africa. A City Wide Approach.

NUSP (2015) National Upgrading Support Programme. Training Manuals, Policies and programmes.

Strauss, M. (2019) A Historical Exposition of Spatial Injustice and Segregated Urban Settlement in South Africa. Fundamina DOI: 10.17159/24117870/2019/v25n2a6. Volume 25 | Number 2 | 2019Print ISSN 1021-545X/ Online ISSN 2411-7870 pp 135-168
Totaforti, S. Urban Planning in PostApartheid South African Cities: The Case of Johannesburg. Open Journal of Political Science, 2020, 10, 507 -520. ISSN Online: 2164-0513.

Ziblim A, Sumeghy A, Sumeghy G (2013) The Dynamics of Informal Settlements Upgrading in South Africa: Legislative and Policy Context, Problems, Tensions, and Contradictions. 